\title{
SINERGIA
}

REVISTA DO INSTITUTO DE CIÊNCIAS ECONÔMICAS, ADMINISTRATIVAS E CONTÁBEIS (ICEAC)

\section{MICROCRÉDITO: UM ESTUDO DE CASO NO PROGRAMA CREDIAMIGO DO BANCO DO NORDESTE DO BRASIL}

MARCELO GOMES CUNHA JOANNA DARC KIRSCHNER FREIRE*

\section{RESUMO}

O Microcrédito pode cumprir um papel estratégico no campo das políticas públicas de trabalho e renda, visto não como uma política compensatória, mas como elemento de uma perspectiva mais ampla de integração de empreendimentos populares ou de pequeno porte no processo de desenvolvimento. O presente trabalho tem por objetivo estudar o Programa Crediamigo, do Banco do Nordeste do Brasil, com enfoque na geração de emprego e renda, verificando suas características e sistemática, comparando-o com outros programas de microcrédito no Brasil e na América Latina, para apontar suas vantagens. A pesquisa desenvolvida para esse fim foi de natureza essencialmente qualitativa, sendo um estudo de caso, de caráter descritivo, em que os dados foram coletados por meio da aplicação de questionário aos seis gestores das instituições de microcrédito cadastradas no SEBRAE-RN para intermediar a modalidade de crédito em estudo. Os dados foram tratados por meio de análise descritiva. Os principais resultados são: o programa facilita o acesso ao crédito a empreendedores que desenvolvem atividades relacionadas à produção; alguns paradigmas foram quebrados, tais como, os clientes que ganham pouco não pagam seus empréstimos, a baixa inadimplência demonstra o inverso e que os empreendimentos são lucrativos a ponto de atrair investimentos privados.

Palavras-Chave: Microcrédito. Microeempreendedorismo. Crediamigo.

\section{ABSTRACT}

MICROCREDIT: A CASE STUDY OF THE BANCO DO NORDESTE CREDIAMIGO PROGRAM

Microcredit can play a strategic role in the field of public policies on employment and income, not seen as a compensatory policy, but as part of a broader integration of popular new developments or smaller in the development process. This paper aims to study the program Crediamigo, the Banco do Nordeste do Brasil, focusing on employment and income generation, checking its characteristics and systematic and comparing it with other microcredit programs in Brazil and Latin America, to point out its advantages. The research undertaken for this purpose was essentially qualitative, and a case study and descriptive, when the data were collected by means of interviews with six managers of microfinance institutions registered in SEBRAE-RN to mediate the type of credit study. The data were treated through descriptive analysis of variables found. The main results are described as: BNB Program facilitates access to credit to entrepreneurs who develop activities related to production, some paradigms have been broken, such as customers who earn low wages do not pay their loans, the low default rate and the reverse shows that enterprises are profitable enough to attract private investment.

Keywords: Microcredit. microentrepreneurship. Crediamigo.

Recebido em: 02-01-2017 Aceito em: 29-10-2017

\section{INTRODUÇÃO}

Segundo Carmo (2005), o crédito caro dificulta a vida de quem deseja produzir, já que dificilmente o produtor consegue arcar com as taxas de juros cobradas pelas instituições bancárias, às vezes superiores a $50,0 \%$ de juros ao ano sobre o valor emprestado. Se, para o grande e o médio produtor, as taxas de juros cobradas pelas instituições financeiras são elevadas, o acesso ao crédito fica custoso, consequentemente, inviável ao pequeno produtor, pois este normalmente não possue garantias.

Para Carmo (2005), uma nova modalidade de crédito vem crescendo e já é considerado por muitos analistas como um instrumento de desenvolvimento econômico: o microcrédito. Na visão de Carmo (2005), o microcrédito é uma das saídas possíveis para viabilizar os empréstimos a esses microprodutores, que se revelam, na sua maioria, empresas informais, sem contar, inclusive, com o registro de pessoa jurídica (CNPJ), conforme menciona o Estudo da Economia Informal (ECINF), publicado pelo Instituto Brasileiro de Geografia e Estatística (IBGE), no ano de 1999.

\footnotetext{
*Universidade Potiguar - UNP

"Universidade Potiguar - UNP
} 
Entre os serviços bancários, o crédito se destaca como o mais importante para que um empreendimento se desenvolva. Sem ele, é difícil uma empresa se manter funcionando. Para os microempreendedores, a dificuldade em obter crédito ocorre em muitos casos, decorrentes da falta de garantias reais exigidas pelos bancos tradicionais e de acesso a serviços financeiros adequados aos seus negócios. Isso faz com que percam oportunidades de crescimento e acabem recorrendo a empréstimos de amigos, familiares e agiotas.

Segundo Silveira (2008), a indisponibilidade de crédito para microempreendedores faz do microcrédito uma alternativa de desenvolvimento econômico, contribuindo para o resgate da cidadania e elevação da dignidade e autoestima dos mesmos.

Dada as dificuldades encontradas pelos microempreendedores para conseguir crédito, o SEBRAE verificou, por meio de uma pesquisa, publicada na Revista Microfinanças SEBRAE (2007), as razões pelas quais as instituições não ofertam empréstimos, conforme transcrito abaixo:

QUADRO 1 - Razões alegadas pelas instituições financeiras para não ofertar empréstimos às pequenas e médias empresas - 2003

\begin{tabular}{|l|c|}
\hline \multicolumn{1}{|c|}{ MOTIVO ALEGADO } & PERCENTUAL \\
\hline Falta de Garantias Reais & $40 \%$ \\
\hline Registro no CADIN/SERASA & $16 \%$ \\
\hline Insuficiência de documentos & $12 \%$ \\
\hline Inadimplência da empresa & $9,0 \%$ \\
\hline Linhas de crédito fechadas & $7,0 \%$ \\
\hline Projeto inviável & $4,0 \%$ \\
\hline Outras & $12,0 \%$ \\
\hline
\end{tabular}

FONTE: SEBRAE (2003)

\section{REFERENCIAL TÉORICO}

\subsection{Definições de microcrédito}

De acordo com Fernandez (2003), o microcrédito é definido como qualquer crédito concedido a um mutuário, se um indivíduo ou entidade jurídica, ou a um grupo de mutuários assumindo responsabilidade solidária de empréstimo destinado a financiar a pequena produção, comercialização ou serviços de atividades. Segundo o autor, a principal fonte de pagamento do empréstimo são as receitas de vendas ou de receitas geradas por estas atividades, como devidamente verificadas pela instituição de empréstimos do sistema financeiro.

Microcrédito é a concessão de empréstimos de baixo valor a pequenos empreendedores informais e microempresas sem acesso ao sistema financeiro tradicional, principalmente por não terem como oferecer garantias reais (BARONE, 2002).

Microcrédito é a extensão de pequenos empréstimos para empreendedores muito pobres para qualificar empréstimos de bancos tradicionais. Isso provou uma medida popular e efetiva na luta contra a pobreza. O microcrédito alavanca as pequenas empresas com pequenos montantes para empreendedores (Grammen banking for the poor, 2000).

De acordo a Revista SEBRAE Microcrédito (2005), microcrédito é uma modalidade de financiamento destinada aos micro e pequenos negócios. Suas principais características:

i) acompanhamento do Microempreendedor no local onde ele atua - diminui a inadimplência;

ii) a maior concentração da concessão é para microempreendedor da economia formal e informal; e Operações de menor monta que o sistema creditício tradicional.

Como forma buscar o entendimento quanto à definição de microcrédito, o Quadro 2 resume e compara algumas definições de microcrédito, previstas no regime jurídico em vigor em dois países da América Latina. 


\begin{abstract}
Bolivia
Em síntese, seria: "microcrédito" é definido como um crédito concedido ao mutuário, se um indivíduo ou uma entidade jurídica, ou um grupo de mutuários assumindo conjuntas ou várias responsabilidades por empréstimo reembolso, destinado a financiar a pequena produção, comercialização ou atividades de serviços, com a principal fonte de pagamento a ser o produto de vendas ou de receitas geradas por essas atividades, como adequadamente verificadas. A aprovação desses créditos deve ser "apoiada" por uma verificação e análise da situação financeira do mutuário, mostrando capacidade de reembolso, tendo em conta a real capacidade de honrar a responsabilidade solidária assumida para empréstimo reembolso, no caso de omissão ou falta de pagamento por um ou mais codevedores. Análise deve necessariamente incluir pedido de relatórios para o Centro de informação sobre os riscos da SBEF, bem como a outras fontes de informações de crédito.
\end{abstract}

\title{
Colômbia
}

Em síntese, seria: Todas as instituições sob a supervisão [da presente Superintendência] devem classificar microcrédito como o conjunto de ativos de operações de crédito concedido à microempresa, cujo saldo, em dívida com a respectiva instituição não deve exceder vinte e cinco (25) vezes o salário mínimo mensal legal atual. "Microempresa" é qualquer unidade da exploração econômica, operada ou por um indivíduo ou uma entidade jurídica, que exerça atividades empresariais, agrícolas, industriais, comerciais ou de serviços, rural ou urbana, com salários que não ultrapassem dez (10) trabalhadores, e total de ativos sob quinhentos e uma (501) vezes o salário mínimo mensal legal atual.

FONTE: Rosales, (2002).

\subsection{A oferta de microcrédito no Brasil}

De acordo com Neri (2005, p.43), "o mercado de crédito brasileiro privilegia mais o consumidor do que o produtor". Segundo o autor, é mais de curto do que de longo prazo e atinge mais a alta do que a baixa renda. Neri (2005) destaca a ênfase apresentada, que a escassa oferta de microcrédito é de natureza pública, e não privada, gerando potenciais ineficiências alocativas. Para o professor Vega-Gonzalez, da Universidade de Ohio, estes vieses podem ser sintetizados, o que chamou de "mistério brasileño" em palestra no BNDES, em 1997.

Neri (2005) relata que o mesmo defende a ideia de que a falta de capital coletável por parte dos pobres faz com que eles não tenham acesso a crédito formal e que seus ativos tenham baixo valor de mercado. Segundo o autor, o valor total dos imóveis de posse extralegal dos pobres no Terceiro Mundo e nas nações do extinto bloco comunista é de pelo menos US $\$ 9,3$ trilhões, o que é 93 vezes mais do que todo o auxílio para o progresso concedido por todos os países desenvolvidos ao Terceiro Mundo no mesmo período (em 1997).

Mezzera (2006) cita que, em 2000, havia, no Brasil, em torno de seis milhões de clientes prováveis de microcrédito com uma demanda de aproximadamente $\mathrm{R} \$ 11$ bilhões. Porém, nessa mesma época, as instituições de microcrédito somente atendiam cerca de 115 mil clientes com uma carteira ativa de $\mathrm{R} \$ 85$ milhões.

\subsection{A demanda por microcrédito}

De acordo com o Fórum de Microfinanças (2007), estimativas realizadas pelo SEBRAE sobre o potencial do mercado brasileiro de microcrédito revelam a existência de 9,5 milhões de pequenos empreendedores e cerca de 13 milhões de pessoas sem acesso ao crédito junto ao sistema financeiro tradicional. Assim, além de se apresentar como uma excelente oportunidade de negócio, o microcrédito é visto pelas organizações nacionais e internacionais como a alternativa mais promissora de se possibilitar aos pequenos empreendedores, sobretudo àqueles mais carentes da sociedade, o acesso ao crédito. Segundo Neri, apud Stiglitz e Greenwald (2003), "a necessidade de focar o papel do crédito para contribuir com a atividade econômica de uma maneira geral, também destacando o papel da informação na determinação de quem toma o crédito e o papel dos bancos neste processo".

Berger e Undel (1998) estudam a possibilidade de obter as fontes de crédito em função do tamanho, idade e disponibilidade de informação da empresa. Os autores demonstram que empresas pequenas e empresas recém-criadas são financiadas pelas suas famílias e amigos. À medida que as empresas crescem, elas obtêm acesso a crédito por intermediação financeira e a créditos bancários. E se a empresa continuar a crescer, ela provavelmente terá acesso a contratos com a administração pública e ao mercado de crédito. 


\section{METODOLOGIA}

Este estudo é caracterizado como uma pesquisa descritiva e de campo. Foram, ainda, utilizadas as pesquisas bibliográfica e documental.

O universo objeto deste estudo é constituído pelos seis (6) gestores de microcrédito, cadastrados no SEBRAE para operar com Microcrédito no Município de Natal, sendo 03 deles Gerentes das Agências dos Bancos Públicos da Cidade do Natal que trabalham com o microcrédito. Foram pesquisados todos os gestores, consolidando, portanto, a pesquisa como censitária.

\subsection{Definição das variáveis}

Fundamentado em estudos do Banco Mundial, do PREALC (Programa Regional de Emprego para América Latina e Caribe) e nas práticas de alguns dos estudiosos apoiadores destes programas de microcrédito, a presente análise será articulada com base: a) no foco do programa; b) na forma de composição do fundo; c) nos instrumentos de prestação de serviços do microcrédito; d) na sustentabilidade e em suas estratégias; e) nas estratégias para expansão. Dessa forma, foi elaborado um Quadro com avaliação comparativa das atividades dos programas de microcrédito.

\section{- Os critérios de avaliação:}

a) Foco: De acordo com Ledgerwood (1999), entende-se por foco a categoria socioeconômica da população que está sendo beneficiada pelo programa de microcrédito.

b) Forma de composição do fundo: Para Matos (2007), as organizações de microcrédito operam a partir da disponibilização de recursos reunidos em um fundo financeiro destinado para a concessão de crédito, sua carteira de empréstimos.

c) Instrumentos de prestação de serviços do microcrédito: De acordo com Ledgerwood (1999), os principais instrumentos de microcrédito diferenciam estes serviços dos utilizados pelas intermediárias de crédito convencionais, apresentando soluções para alguns problemas relacionados com a assimetria de informação subjacente ao mercado de crédito.

d) Sustentabilidade e suas estratégias: De acordo com Morduch (1999), muitos programas de microcrédito continuam sendo subsidiados diretamente através de doações e indiretamente, a partir de termos contratuais muito exigentes. Entretanto, é comum que os programas de menor sustentabilidade sejam aqueles que mais se desviem de um dos propósitos do microcrédito: servir a população de baixa renda.

e) Estratégias para expansão: Para Matos (2007), um dos problemas dos programas de microcrédito é sua escassa cobertura em relação ao universo de potenciais usuários. Segundo o autor, interessa reconhecer qual a capacidade de expansão dos programas de microcrédito para atender sua clientela potencial e, sobretudo, quais as barreiras que os impedem de se expandir.

\section{APRESENTAÇÃO E ANÁLISE dOS RESULTADOS}

\section{Primeira Parte}

\subsection{Comparação entre o programa Crediamigo e outros programas de microcrédito}

4.1.1 Avaliação comparativa das atividades dos programas de microcrédito

A avaliação se fará a partir da análise comparativa entre os 5 pontos de maior destaque presentes nos programas de microcrédito. A justificativa para escolha destes pontos comuns é pautada na literatura como os pontos cruciais que estabelecem os diferenciais do microcrédito. A referência utilizada demonstra o crescente interesse que a atividade de microcrédito vem despertando, seja no campo das estratégias de agentes do mercado seja na concepção de políticas públicas.

Tendo em vista os 5 tópicos apontados na metodologia, a síntese relacionada a esta temática será representada abaixo por meio da análise dos programas de microcrédito até aqui apresentados.

Programas de Microcrédito no Brasil - Foram relacionados os programas estudados, apresentando, de acordo com os critérios pré-estabelecidos, as principais diferenças encontradas. 
QUADRO 3 - Avaliação comparativa das atividades dos programas de microcrédito

\begin{tabular}{|c|c|c|c|c|c|}
\hline Características & CEAPE & PORTOSOL & BNDES & ANDE & CREDIAMIGO \\
\hline $\begin{array}{c}\text { Geral - Área } \\
\text { geográfica }\end{array}$ & Áreas Urbanas & Áreas urbanas & $\begin{array}{c}\text { Áreas Urbanas e } \\
\text { Rurais }\end{array}$ & Áreas Urbanas & $\begin{array}{c}\text { Áreas Urbanas e } \\
\text { Rurais }\end{array}$ \\
\hline $\begin{array}{c}\text { Foco - Tipo de } \\
\text { Clientes e valor de } \\
\text { empréstimos }\end{array}$ & $\begin{array}{c}\text { Micro } \\
\text { Empreendedores } \\
\text { de baixa renda. } \\
\text { Variam de } \mathrm{R} \$ 200 \mathrm{a} \\
3.000 \text {, ou mais. }\end{array}$ & $\begin{array}{c}\text { Pequenos } \\
\text { empreendedores de } \\
\text { ambos os sexos para } \\
\text { capital de giro e } \\
\text { capital fixo. } \\
\text { Empréstimos de } \\
R \$ 200,00 \text { a } \\
15.000,00\end{array}$ & $\begin{array}{c}\text { Pessoas físicas e } \\
\text { jurídicas } \\
\text { empreendedoras de } \\
\text { atividades produtivas } \\
\text { de pequeno porte e o } \\
\text { valor máximo é de } \mathrm{R} \$ \\
10.000,00 \text { por } \\
\text { beneficiário. }\end{array}$ & $\begin{array}{c}\text { Micro } \\
\text { empreendedores de } \\
\text { pequeno porte. } \\
\text { Até } \mathrm{R} \$ 7.000,00\end{array}$ & $\begin{array}{c}\text { Micro } \\
\text { Empreendedores, } \\
\text { principalmente as } \\
\text { mulheres (acima } \\
\text { de } 60 \% \text { ), os } \\
\text { empréstimos } \\
\text { variam de } \mathrm{R} \$ 100 \\
\text { a } 2 \text { mil }\end{array}$ \\
\hline $\begin{array}{c}\text { Composição do fundo } \\
\text { - Origem dos Fundos } \\
\text { e Tamanho da } \\
\text { Carteira }\end{array}$ & $\begin{array}{c}\text { Financiamentos } \\
\text { Comerciais e } \\
\text { verbas do BID e } \\
\text { BNDES }\end{array}$ & $\begin{array}{l}\text { Financiamentos } \\
\text { Comerciais e } \\
\text { Governamentais }\end{array}$ & $\begin{array}{l}\text { Depósitos e } \\
\text { Diversidade de } \\
\text { Financiamentos }\end{array}$ & $\begin{array}{l}\text { Diversidade de } \\
\text { Financiamentos }\end{array}$ & $\begin{array}{l}\text { Recursos do BID, } \\
\text { BIRD, FAT e } \\
\text { BNDES. }\end{array}$ \\
\hline $\begin{array}{l}\text { Instrumentos - } \\
\text { Exigência de garantia }\end{array}$ & $\begin{array}{l}\text { Aval Solidário e } \\
\text { empréstimos } \\
\text { solidários }\end{array}$ & $\begin{array}{c}\text { É definido por meio } \\
\text { de análise do projeto } \\
\text { em conversa informal } \\
\text { para avaliar o } \\
\text { comprometimento da } \\
\text { família com o negócio }\end{array}$ & $\begin{array}{c}\text { A ser definido na } \\
\text { análise da operação. }\end{array}$ & Aval Solidário & $\begin{array}{c}\text { Aval Solidário e } \\
\text { coobrigação }\end{array}$ \\
\hline $\begin{array}{c}\text { Sustentabilidade - } \\
\text { Encargos Financeiros } \\
\text { e Inadimplência }\end{array}$ & $\begin{array}{l}\text { A taxa de juros é de } \\
5,5 \% \text { a.m., e a } \\
\text { inadimplência é de } \\
\text { acordo com o } \\
\text { estado, por } \\
\text { exemplo, em PE, é } \\
\text { de } 3,2 \%\end{array}$ & $\begin{array}{l}\text { A taxa de juros é de } \\
2 \% \text { a.m, e a } \\
\text { inadimplência é } \\
\text { considerada } \\
\text { compatível com o } \\
\text { mercado em } 4,25 \%\end{array}$ & $\begin{array}{l}\text { A taxa de juros é de } \\
4 \% \text { a.m e a } \\
\text { inadimplência é } \\
\text { variável entre } 2 \text { e } 5 \% \\
\text { (fonte BNDES) }\end{array}$ & $\begin{array}{c}\text { A taxa de juros } \\
\text { varia entre } 2,9 \% \\
\text { a.m a 3,99\% a.m e } \\
\text { inadimplência é de } \\
3 \%\end{array}$ & $\begin{array}{l}\text { A taxa de juros } \\
\text { varia de } 1,32 \% \\
\text { a.m } 2 \% \text { a.m. A } \\
\text { média da taxa de } \\
\text { inadimplência é } \\
\text { menor que } 1 \%\end{array}$ \\
\hline $\begin{array}{l}\text { Expansão - Clientes } \\
\text { Ativos na Carteira }\end{array}$ & $\begin{array}{c}\text { O número de } \\
\text { cliente ativos é de } \\
69.000 \text {. A intenção } \\
\text { é ampliar a carteira } \\
\text { de clientes para } \\
150 \text { mil em } 2012 \text { e } \\
\text { obter } 80 \% \text { de } \\
\text { satisfação dos } \\
\text { clientes. }\end{array}$ & $\begin{array}{l}\text { A carteira ativa atual } \\
\text { é de } 2047 \text { clientes. A } \\
\text { intenção é atuar por } \\
\text { meio de SCM nos } \\
\text { estados e municípios, } \\
\text { aumentando seu } \\
\text { portfólio }\end{array}$ & $\begin{array}{c}\text { Aumentar os } \\
\text { desembolsos } \\
\text { financeiros em } 23 \% \\
\text { na região nordeste e } \\
38 \% \text { no sudeste. }\end{array}$ & $\begin{array}{l}\text { Atuar em vários } \\
\text { estados por meio } \\
\text { de OSCIP. }\end{array}$ & $\begin{array}{l}\text { Possui mais de } \\
55000 \text { clientes } \\
\text { ativos e atua em } 9 \\
\text { estados do } \\
\text { nordeste. }\end{array}$ \\
\hline
\end{tabular}

FONTE: Elaboração dos Autores

A seguir tem-se o Quadro 4, que trata de outros programas de microcrédito em outros países da América Latina. Foram selecionados para efeito de comparação os dois principais programas de microcrédito da Bolívia e um da Colômbia.

QUADRO 4 - Programas de Microcrédito na América Latina

\begin{tabular}{|c|c|c|c|}
\hline Características & BancoSol & Caja Los Andes & Corposol \\
\hline Geral - Área geográfica & Áreas Urbanas e Rurais & Áreas urbanas & Áreas Urbanas e Rurais \\
\hline $\begin{array}{l}\text { Foco - Tipo de Clientes e } \\
\text { valor de empréstimos }\end{array}$ & $\begin{array}{l}\text { - Não consta em sua } \\
\text { carteira um foco específico; } \\
\text { - Valor médio é de U\$ } 431\end{array}$ & $\begin{array}{c}\text { Microempreendedores de } \\
\text { ambos os sexos e População } \\
\text { de Baixa Renda. O valor médio } \\
\text { é de U\$560 }\end{array}$ & $\begin{array}{l}\text { Microempreendedores. A média de } \\
\text { financiamento de U\$500, mínimo } \\
\text { de U\$ } 100 \text { e máximo de U\$5.000 }\end{array}$ \\
\hline $\begin{array}{l}\text { Composição do fundo - } \\
\text { Origem dos Fundos e } \\
\text { Tamanho da Carteira }\end{array}$ & $\begin{array}{c}\text { Transferências do BNB e } \\
\text { Banco Mundial }\end{array}$ & $\begin{array}{l}\text { Financiamentos Comerciais e } \\
\text { Governamentais }\end{array}$ & $\begin{array}{l}\text { Depósitos e Diversidade de } \\
\text { Financiamentos }\end{array}$ \\
\hline $\begin{array}{c}\text { Instrumentos - Exigência } \\
\text { de garantia }\end{array}$ & Aval Solidário & Consignação ou aval solidário & $\begin{array}{l}\text { A garantia pode ser real, alienação } \\
\text { do bem financiado, avalista ou aval } \\
\text { solidário. }\end{array}$ \\
\hline $\begin{array}{c}\text { Sustentabilidade - } \\
\text { Encargos Financeiros e } \\
\text { Inadimplência }\end{array}$ & $\begin{array}{l}\text { A taxa de juros é } 5 \% \text { a.m e } \\
\text { a inadimplência é de } 4 \% \text { a.m }\end{array}$ & $\begin{array}{l}\text { A taxa de juros é } 5,5 \% \text { a.m, e a } \\
\text { inadimplência é de } 4 \% \text {. }\end{array}$ & $\begin{array}{l}\text { A taxa de juros é de } 4 \% \text { a.m., e a } \\
\text { carteira de inadimplentes é de } \\
\text { aproximadamente } 0 \% \text { no setor rural } \\
\text { e chega a } 3 \% \text { a.m. na área urbana }\end{array}$ \\
\hline $\begin{array}{l}\text { Expansão - Clientes } \\
\text { Ativos na Carteira }\end{array}$ & $\begin{array}{c}\text { A carteira é de } 38.786 \\
\text { clientes ativos, com intenção } \\
\text { de atuar em outros } \\
\text { munícipios }\end{array}$ & $\begin{array}{c}\text { A carteira é de } 23.310 \text {, está em } \\
\text { busca de parcerias }\end{array}$ & $\begin{array}{c}\text { Atuam em três departamentos } \\
\text { (equivalente a Estado no Brasil) e } \\
\text { têm } 27 \text { agências. }\end{array}$ \\
\hline
\end{tabular}

FONTE: Baseada nos estudos de Franco de Matos e de Labie Mar (2007) 


\section{- Avaliação Comparativa}

Com base nos critérios apurados no quadro acima, pode-se verificar que existem parâmetros de eficácia que permitem avaliar o foco dos programas de microcrédito, pois, Segundo Matos (2007), os critérios de seleção do público-alvo (rendimento familiar, posses etc) podem fornecer uma informação mais apurada dos tomadores de crédito contemplados pelos programas de microcrédito, ou seja, analisar se, de fato, os excluídos do mercado de crédito formal estão inseridos neste contexto.

Hulme e Mosley (1996) acreditam que a focalização nos mais pobres não proporciona maior impacto sobre a pobreza, já que esses clientes têm menos condições de realizar investimentos produtivos. A efetividade do microcrédito seria maior quando os empréstimos fossem tomados por microempreendedores menos pobres, os quais poderiam realizar melhores investimentos e gerar maior retorno sobre os recursos investidos.

No que tange ao segundo tópico analisado, à composição dos fundos e ao tamanho da carteira, observa-se que os programas de microcrédito ativos na Bolívia apresentam valores disponíveis maiores que outros programas. Segundo Matos (2007), o Banco Comercial boliviano BancoSol tem carteira muito superior à experiência brasileira de integração do microcrédito ao sistema financeiro convencional, sendo o Crediamigo o de montante maior no caso brasileiro. Cabe ressaltar que, de acordo com Goldmark (2000), o Crediamigo conta, também, com financiamento de outras linhas de crédito do BNB, não subsidiadas (é importante frisar que, embora se constitua em um programa interno a uma instituição financeira convencional, o Crediamigo não se vale de captação de poupança articulada com sua carteira de empréstimos). Outro ponto destacado por Matos (2007) é que o BNDES é um financiador potencial dos programas de microcrédito da Portosol e dos Ceapes.

A utilização dos instrumentos de microcrédito com uma combinação de serviços é destacada por Matos (2007) como imprescindível para garantir os objetivos de um programa de microcrédito. Por meio do quadro de análise, pode-se verificar que o aval solidário, garantias e parcelamento do pagamento são muito utilizados e considerados pelos programas de microcrédito, que se valem dos serviços de apoio técnico ao empreendedor para consolidar a parceria entre a instituição e o microempreendedor. De acordo com Morduch (1999), o aval solidário reduz os efeitos negativos da assimetria de informação existente entre a Instituição Microfinanceira (IMF) e os seus clientes, tais como a seleção adversa e o risco moral.

No aspecto sustentabilidade, verifica-se que o controle da taxa de inadimplência é latente e primordial nos programas de microcrédito, principalmente para não comprometer sua sustentabilidade. Para Schoenberg (2000), a inexistência de uma metodologia única para construção de indicadores de sustentabilidade comuns entre os programas não permite um aprofundamento analítico financeiro.

Cabe ressaltar que a sustentabilidade financeira fundamenta-se em dois níveis: a capacidade de alavancar recursos para o fundo e sua política de crédito - capaz de tornar a instituição autônoma e atingir rapidamente seu ponto de equilíbrio (Ibam, 2001). No que se refere à política de crédito, a sustentabilidade depende da cobrança de juros que cubram os custos totais de execução do programa e de um sistema eficiente de recuperação dos empréstimos, de modo a manter baixas as taxas de inadimplência (Passos et al., 2002).

Finalmente, no aspecto de expansão, a capacidade dos programas de microcrédito está condicionada a parâmetros, que, segundo Matos (2007), estão ligados ao tamanho da clientela ativa e ao ambiente institucional em que se inserem os programas.

\subsection{Vantagens e Desvantagens}

O quadro a seguir busca apresentar os aspectos comparativos do Crediamigo e outros programas estudados. A fim de estabelecer critérios comuns aos programas elencados neste estudo, foram identificados 13 pontos cruciais e considerados condicionantes para o funcionamento de um programa de microcrédito. De acordo com Ledgerwood (1999), os principais instrumentos de microcrédito diferenciam estes serviços dos utilizados pelas intermediárias de crédito convencionais. 
QUADRO 5 - O Crediamigo x Outros Programas

\begin{tabular}{|c|c|c|}
\hline Tópicos Comparados & Crediamigo & Outros Programas \\
\hline Carteira de Clientes & Em média 200 mil clientes & No máximo 175 mil clientes \\
\hline Inadimplência & $0,96 \%$ & Acima de $2 \%$ \\
\hline $\begin{array}{l}\text { Metodologia de concessão de } \\
\text { crédito }\end{array}$ & $\begin{array}{c}\text { Aval Solidário. Adotam Informalidade } \\
\text { na avaliação de crédito - visita ao } \\
\text { local de trabalho e questionamento } \\
\text { informal. }\end{array}$ & $\begin{array}{l}\text { Utilização de diversas metodologias de } \\
\text { concessão de crédito - Aval Simples, } \\
\text { alienação de bens, dentre outros. }\end{array}$ \\
\hline Prazo de Pagamento & Até 12 meses & Em média 18 meses \\
\hline Atuação no Brasil & $\begin{array}{l}\text { Presente em } 9 \text { Estados - Possui } \\
60 \% \text { do mercado nacional }\end{array}$ & $\begin{array}{c}\text { Depende da ONG que atua, podendo ser } \\
\text { somente local. Por exemplo, a Portosol } \\
\text { somente atua no RS. }\end{array}$ \\
\hline Valor de Empréstimo & $\mathrm{De} R \$ 100$ a $R \$ 10 \mathrm{mil}$ & De $R \$ 200$ a $R \$ 15$ mil \\
\hline Tempo de liberação do crédito & Até 7 dias úteis & $\begin{array}{l}\text { Dependendo do tipo de crédito, pode } \\
\text { levar até } 5 \text { dias úteis }\end{array}$ \\
\hline Quantidade de Produtos & Possuem mais de 5 produtos & Entre 1 e 5 produtos \\
\hline Parcerias & $\begin{array}{c}\text { Realização de Parcerias com outras } \\
\text { instituições - VivaCred (OSCIP), } \\
\text { oferencendo, inclusive, serviços } \\
\text { financeiros } \\
\end{array}$ & $\begin{array}{c}\text { Somente atuam por meio de ONG e não } \\
\text { podem oferecer serviços financeiros, } \\
\text { apenas aquelas que se vinculam a } \\
\text { financeiras. }\end{array}$ \\
\hline Taxas de Juros & $\begin{array}{c}\text { Em média } 2 \% \text { ao mês + Taxas } \\
\text { operacionais }\end{array}$ & $\begin{array}{c}\text { Em média, entre } 2,99 \% \text { a } 4 \%+\text { Taxas } \\
\text { operacionais }\end{array}$ \\
\hline Acompanhamento do Crédito & $\begin{array}{l}\text { Em até } 45 \text { dias os créditos novos ou } \\
\text { com atrasos são acompanhados. } \\
\text { Atuação com Agentes de Crédito da } \\
\text { própria comunidade, formados pelo } \\
\text { próprio BNB, em detrimento a } \\
\text { especialistas. }\end{array}$ & $\begin{array}{l}\text { O acompanhamento é esporádico. } \\
\text { Alguns possuem Dificuldade em } \\
\text { captação de mão-de-obra especializada } \\
\text { - Agentes de Crédito }\end{array}$ \\
\hline Público alvo & Economia Formal e Informal & $\begin{array}{c}\text { Concentrado em microempreendores da } \\
\text { economia informal }\end{array}$ \\
\hline Marketing & $\begin{array}{c}\text { Realização de Benchmarks - } \\
\text { Instituições Estrangeiras. De acordo } \\
\text { com Neri (2008): } \\
\text { O CrediAmigo é o segundo maior } \\
\text { programa de microcrédito da } \\
\text { América Latina. Divulgação por meio } \\
\text { da mídia de TV e jornais, além de } \\
\text { publicação em site seus relatórios } \\
\text { com resultados. Possuem modelo de } \\
\text { rede de microfinanças. }\end{array}$ & $\begin{array}{l}\text { Apresentam resultados em seus sites } \\
\text { próprios. Estão em fase de construção } \\
\text { de modelos de microfinanças. }\end{array}$ \\
\hline
\end{tabular}

FONTE: Elaboração dos Autores

Com a apresentação da tabela, foi possível identificar alguns pontos cruciais de desvantagem do Crediamigo em relação a outros programas estudados, tais como:

i) O Crediamigo leva até 7 dias para liberar o crédito, ao passo que outros programas demoram um pouco menos; e

ii) $O$ valor dos empréstimos e prazos de pagamentos de outros programas são maiores que o Crediamigo, outros programas utilizam diversas metodologias de concessão de crédito, ao passo que 0 Crediamigo se concentra no aval solidário. programas.

Cabe ressaltar que, nos outros pontos, o Crediamigo apresentou vantagens em relação a outros

\subsection{Resultado da pesquisa apurada pelos questionários}

\section{Segunda Parte:}

Para alcançar os objetivos do estudo, foi aplicado um questionário com o universo dos gestores dos programas de microcrédito do município do Natal/RN, que serviu de suporte para o alcance dos objetivos específicos deste trabalho. Foram identificadas seis instituições que participam desta modalidade de crédito e distribuídos questionários para identificar o perfil do gestor do programa e peculiaridades do microcrédito utilizado pela instituição, são elas: Banco do Nordeste, Credinatal, CEAPE-RN, ANDE, Banco Real e Banco do Brasil. Foram identificados 6 pontos importantes a serem pesquisados: Informações Relativas ao Programa de Microcrédito, Aspectos Relativos à Concessão de Crédito, Informações Relativas ao Acompanhamento do Crédito Concedido, Informações Relativas a Histórias de Sucesso do Programa e 
Aspectos Relativos à Instituição.

Dentre os questionários distribuídos, apenas o gestor da ANDE não respondeu. Ao comparecer à unidade da ANDE em Natal/RN, foi possível constatar que o escritório foi desativado. Segue abaixo a análise das respostas:

QUADRO 5 - Resultado do Questionário

\begin{tabular}{|c|c|c|c|}
\hline Aspectos Pesquisados & Tópicos & Resultados Apurados & Comentários \\
\hline \multirow{4}{*}{ 1) Informações Gerais } & Sexo & $\begin{array}{l}83 \% \text { são do sexo feminino e } 17 \% \\
\text { do Sexo Masculino. }\end{array}$ & $\begin{array}{l}\text { No munícipio de Natal, há indícios de } \\
\text { liderança majoritariamente no ramo. }\end{array}$ \\
\hline & Função na Instituição & $\begin{array}{l}\text { Todos exercem a função de } \\
\text { Administrador/Gerente. }\end{array}$ & $\begin{array}{l}\text { Confirma a importância deste nicho de } \\
\text { mercado }\end{array}$ \\
\hline & Experiência & $\begin{array}{l}\text { Os gestores da Credinatal e } \\
\text { CEAPE-RN possuem mais de } 05 \\
\text { anos de experiência. }\end{array}$ & $\begin{array}{c}\text { Credibiliza ainda mais as informações } \\
\text { ora prestadas. }\end{array}$ \\
\hline & Tempo na Instituição & $\begin{array}{c}\text { 50\% dos gestores está há mais de } \\
10 \text { na instituição. }\end{array}$ & $\begin{array}{l}\text { Facilita o entendimento da importância } \\
\text { do microcrédito e a solidez do gestor } \\
\text { na função }\end{array}$ \\
\hline \multirow{5}{*}{$\begin{array}{l}\text { 2) Programa de } \\
\text { Microcrédito }\end{array}$} & Captação de Clientes & $\begin{array}{l}60 \% \text { captam seus clientes por meio } \\
\text { de visitas ao local de trabalho e } \\
20 \% \text { se valem do intermediário de } \\
\text { crédito. }\end{array}$ & $\begin{array}{l}\text { Cabe ressaltar que a aproximação da } \\
\text { instituição e do tomador de } \\
\text { empréstimo reduz consideravelmente } \\
\text { a possibilidade de insucesso do } \\
\text { empreendimento. }\end{array}$ \\
\hline & $\begin{array}{l}\text { Avaliação técnica do } \\
\text { negócio }\end{array}$ & $\begin{array}{l}75 \% \text { dos gestores utilizam a } \\
\text { ferramenta do questionário. }\end{array}$ & $\begin{array}{l}\text { Conforme Securato (2006) é uma } \\
\text { ferramenta eficaz e bastante comum } \\
\text { no mercado }\end{array}$ \\
\hline & Capacidade de empréstimo & $\begin{array}{c}31 \% \text { dos gestores utilizam à história } \\
\text { evolutiva do negócio. }\end{array}$ & $\begin{array}{c}\text { Procuram identificar condições e o } \\
\text { perfil empreendedor. }\end{array}$ \\
\hline & Incoerências identificadas & $\begin{array}{l}75 \% \text { dos gestores responderam } \\
\text { que mostram ao cliente as } \\
\text { incoerências que porventura sejam } \\
\text { identificadas. }\end{array}$ & $\begin{array}{l}\text { Procedimento permite credibilidade e } \\
\text { solidifica a relação entre a instituição e } \\
\text { o cliente. No que tange à sequência } \\
\text { adotada após a captação do } \\
\text { microcrédito. }\end{array}$ \\
\hline & $\begin{array}{l}\text { Custo da Oferta de Crédito } \\
\text { (COC) }\end{array}$ & $\begin{array}{l}50 \% \text { dos gestores responderam } \\
\text { que informa ao cliente o } \\
\text { conhecimento do COC. }\end{array}$ & $\begin{array}{l}\text { É importante para o tomador de } \\
\text { crédito conhecer que encargos estão } \\
\text { sendo imputados no momento da } \\
\text { concessão do crédito. }\end{array}$ \\
\hline \multirow{8}{*}{$\begin{array}{l}\text { 3) Aspectos Relativos à } \\
\text { Concessão de Crédito }\end{array}$} & Público Alvo & $50 \%$ o percentual alcançado. & $\begin{array}{c}\text { Constatou-se um equilíbrio entre } \\
\text { homens e mulheres empreendedoras. }\end{array}$ \\
\hline & Perfil dos clientes & $\begin{array}{l}\text { Mulheres de } 25 \text { anos ou mais, } \\
\text { sendo } 50 \% \text { entre } 25 \text { e } 35 \text { anos e } \\
50 \% \text { com mais de } 35 \text { anos. }\end{array}$ & $100 \%$ da economia informal. \\
\hline & Carteira de Clientes & $\begin{array}{l}1000 \text { clientes cada carteira, em } \\
75 \% \text { dos casos. }\end{array}$ & - \\
\hline & Região do Estado & $\begin{array}{c}\text { 100\% deles são da Região Urbana } \\
\text { (acima de } 50 \% \text { da carteira de } \\
\text { clientes). }\end{array}$ & $\begin{array}{l}\text { Demonstra a ausência da participação } \\
\text { da população rural no acesso ao } \\
\text { microcrédito, e sinaliza aos gestores } \\
\text { uma mudança na estratégia de } \\
\text { captação de clientes, visando atrair } \\
\text { esta faixa da população não atendida }\end{array}$ \\
\hline & Renda média & $\begin{array}{c}\text { Faixa de } 2 \text { a } 5 \text { salários mínimos em } \\
75 \% \text { dos casos. }\end{array}$ & $\begin{array}{l}\text { Não foram identificados clientes com } \\
\text { renda superior a } 5 \text { salários mínimos. }\end{array}$ \\
\hline & $\begin{array}{l}\text { Tempo médio - o tempo } \\
\text { decorrido entre a } \\
\text { apresentação da } \\
\text { documentação do tomador } \\
\text { do crédito e sua efetivação }\end{array}$ & $\begin{array}{c}\text { de } 2 \text { a } 5 \text { dias em } 75 \% \text { dos casos } \\
\text { analisados e } 25 \% \text { acima de cinco } \\
\text { dias. }\end{array}$ & $\begin{array}{l}\text { A demora na efetivação do crédito } \\
\text { pode ser um fator de desestímulo para } \\
\text { o futuro cliente e deve ser controlada } \\
\text { pela instituição, evitando fuga de } \\
\text { clientes ou mesmo não renovação em } \\
\text { contratos. }\end{array}$ \\
\hline & Limite de crédito & $\begin{array}{c}50 \% \text { entre } 500 \text { a } 2000 \text { e } 50 \% \text { acima } \\
\text { de } 5000 .\end{array}$ & $\begin{array}{l}\text { A faixa limite é um termômetro que } \\
\text { permite a instituição elaborar novas } \\
\text { estratégias para aumentar o diminuir a } \\
\text { concessão do crédito }\end{array}$ \\
\hline & Benefícios ou Vantagens & $\begin{array}{l}75 \% \text { das instituições oferecem ou } \\
\text { um seguro ou outro benefício. }\end{array}$ & $\begin{array}{c}\text { Tal procedimento pode ser } \\
\text { considerado como uma maneira de } \\
\text { fidelizar seu cliente, porém não se } \\
\text { pode vincular a concessão à aquisição } \\
\text { de um seguro, para não configurar } \\
\text { uma venda casada, considerada crime } \\
\text { contra o consumidor. }\end{array}$ \\
\hline
\end{tabular}




\begin{tabular}{|c|c|c|c|}
\hline Aspectos Pesquisados & Tópicos & Resultados Apurados & Comentários \\
\hline \multirow[t]{2}{*}{$\begin{array}{l}\text { 4) Acompanhamento do } \\
\text { Crédito Concedido }\end{array}$} & Acompanhamento Posterior & $\begin{array}{l}\text { 75\% dos gestores responderam } \\
\text { que não realizam análise de } \\
\text { desempenho dos clientes após } 01 \\
\text { ano ou menos. }\end{array}$ & $\begin{array}{l}\text { Considerando que o primeiro ano é de } \\
\text { extrema importância para o } \\
\text { empreendedor e que muitas empresas } \\
\text { fecham suas portas no primeiro ano } \\
\text { de vida, o procedimento deve ser } \\
\text { revisto para evitar esses óbices }\end{array}$ \\
\hline & Inadimplência & $\begin{array}{l}75 \% \text { dos gestores informaram ser } \\
\text { entre } 1 \% \text { e } 5 \% .\end{array}$ & $\begin{array}{c}\text { Corroborando ao pressuposto do } \\
\text { microcrédito, que é de baixa } \\
\text { inadimplência, conforme apresentado } \\
\text { no referencial teórico. }\end{array}$ \\
\hline \multirow{3}{*}{$\begin{array}{l}\text { 5) Histórias de Sucesso } \\
\text { do Programa }\end{array}$} & $\begin{array}{l}\text { Melhorias na condição de } \\
\text { vida }\end{array}$ & $\begin{array}{l}100 \% \text { responderam que foi possível } \\
\text { identificar melhorias nas condições } \\
\text { de vida dos demandantes do } \\
\text { crédito do programa oferecido. }\end{array}$ & $\begin{array}{c}\text { Os gestores responderam levando em } \\
\text { consideração a mudança de classe } \\
\text { social. }\end{array}$ \\
\hline & $\begin{array}{l}\text { Subsídio Governamental } \\
\text { (federal, estadual ou } \\
\text { municipal) }\end{array}$ & $\begin{array}{l}75 \% \text { dos gestores responderam } \\
\text { que o programa é autossustentável. }\end{array}$ & $\begin{array}{l}\text { Espera-se, cada vez mais, uma } \\
\text { participação maior dos agentes } \\
\text { públicos. }\end{array}$ \\
\hline & $\begin{array}{l}\text { Impacto do Programa na } \\
\text { economia local }\end{array}$ & 75\% responderam que não. & $\begin{array}{c}\text { A apresentação do impacto na } \\
\text { economia é importante para divulgar a } \\
\text { força do microcrédito e atrair novos } \\
\text { investimentos. }\end{array}$ \\
\hline \multirow{7}{*}{$\begin{array}{l}\text { 6) Aspectos relativos à } \\
\text { Instituição }\end{array}$} & Concorrentes & $\begin{array}{l}100 \% \text { dos gestores informaram } \\
\text { seus concorrentes. }\end{array}$ & $\begin{array}{l}\text { Pode demonstrar o conhecimento da } \\
\text { área em que atuam e quais são suas } \\
\text { forças e fraquezas, suas } \\
\text { oportunidades e ameaças, } \\
\text { instrumentos utilizados em } \\
\text { Planejamento Estratégico. }\end{array}$ \\
\hline & Análise dos Concorrentes & $\begin{array}{l}100 \% \text { responderam que não } \\
\text { realizam análise de desempenho } \\
\text { dos concorrentes. }\end{array}$ & $\begin{array}{l}\text { Cabe ressaltar que conhecer seu } \\
\text { concorrente é fator primordial para o } \\
\text { sucesso em um empreendimento. }\end{array}$ \\
\hline & Estratégias de Marketing & $\begin{array}{l}100 \% \text { dos gestores relataram que } \\
\text { utilizam estratégias de marketing } \\
\text { para divulgar seus programas de } \\
\text { microcrédito. }\end{array}$ & $\begin{array}{l}\text { O mundo atual da globalização não } \\
\text { aceita uma instituição que desconheça } \\
\text { instrumentos de marketing ou não } \\
\text { utilize ferramentas de divulgação }\end{array}$ \\
\hline & Metas & $\begin{array}{l}100 \% \text { dos gestores traçam metas } \\
\text { para a instituição e comparam seus } \\
\text { resultados. }\end{array}$ & \\
\hline & Evolução da Carteira & $\begin{array}{l}75 \% \text { dos casos responderam que } \\
\text { utilizam a medição para verificar a } \\
\text { evolução da carteira de crédito e } \\
\text { número de contratações. }\end{array}$ & \\
\hline & Novas agências & $\begin{array}{l}50 \% \text { dos gestores relataram a } \\
\text { previsão abertura de novas } \\
\text { agências ou expansão da } \\
\text { instituição no município do Natal. }\end{array}$ & $\begin{array}{l}\text { Esta informação pode vir a aumentar a } \\
\text { participação da cidade do Natal no } \\
\text { cenário nacional do microcrédito. }\end{array}$ \\
\hline & Produtos ou Serviços & $75 \%$ oferecem de 1 a 3 produtos. & $\begin{array}{c}\text { Merece uma nova revisão para } \\
\text { aumentar o portfólio da instituição, } \\
\text { visando captar outros clientes ou } \\
\text { oferecer mais produtos e serviços aos } \\
\text { atuais. }\end{array}$ \\
\hline
\end{tabular}

FONTE: Elaboração dos Autores.

Cabem, ainda, as seguintes observações listadas abaixo por item:

1) Neste contexto, a pesquisa apresentou uma considerável dominação do mercado de microcrédito pelo público feminino, na medida em que, não somente a maioria dos gestores bem como o público de muitos programas são mulheres, tal como era o Grameen Bank, com a mesma caracterização.

Face ao exposto, é possível concluir que os gestores que atuam na área de microcrédito de Natal possuem experiência no ramo de microcrédito e podem prestar uma contribuição significativa para esta pesquisa;

2) Somente 15\% utilizam ferramentas como Credit Scoring ou Small Business Scoring, instrumentos que buscam reduzir o nível de inadimplência. No que tange à sequência adotada após a captação do microcrédito, $100 \%$ dos gestores responderam que apresenta ao Comitê de crédito para aprovação, permitindo uma ratificação de outros componentes da instituição;

3) Cabe ressaltar que muitos propensos clientes não buscam esta modalidade de crédito sob a premissa que o mesmo somente é voltado para populações com renda inferior a 5 salários; 
4) A baixa inadimplência encontrada no microcrédito pode ser entendida como um resultado da confiança e baixas taxas de juros desta modalidade de crédito;

5) De acordo com dados recentemente publicados pelo IPEA (Instituto de Pesquisa Econômica Aplicada), nos últimos anos, houve melhorias na condição de vida dos brasileiros, o que não pode ser atribuído $100 \%$ ao sucesso dos programas de microcrédito. Cabe ressaltar um descompasso nas respostas obtidas, pois se, em tópico anterior, os gestores relacionam que não realizam acompanhamento posterior, fica comprometida a afirmação dos mesmos de que é possível identificar melhorias na condição de vida dos demandantes de crédito.

A apresentação do impacto na economia é importante para divulgar a força do microcrédito e atrair novos investimentos. Conforme relata Righetti (2008), o microcrédito é a concessão de empréstimos de valor relativamente pequeno para atividade produtiva tem o potencial de desempenhar o papel de elemento promotor do desenvolvimento social e redutor de pobreza e provoca considerável impacto na economia;

6) No que tange à análise de desempenho, considera-se necessária a mudança de postura dos gestores frente às mudanças mercadológicas em que estão envolvidos o mercado de crédito.

\section{CONCLUSÃO}

O presente trabalho buscou analisar o microcrédito, tendo como seu foco de estudo o Banco do Nordeste, em especial o programa Crediamigo. O Banco do Nordeste foi escolhido como base da pesquisa em virtude de sua participação nacional nesta modalidade de crédito e em face de diversidade de produtos por ele ofertados, sendo o único programa de atendimento direto ao microcrédito implementado por um banco estatal. A seguinte questão foi levantada: como funciona o Programa Crediamigo do BNB e que práticas e sistemáticas poderiam ser adotadas para aumentar sua carteira de clientes e oferta de produtos e serviços.

Com intuito de crescer ainda mais neste mercado, o Banco do Nordeste divulgou, em seu relatório, algumas de suas estratégias para 2009, com o lema "Quem quer crescer não pode parar". O BNB apresentou uma série de estratégias, dentre elas, destacam-se: expandir-se para novos mercados; facilitar o recebimento de recursos pelos clientes; ampliar parcerias com entidades públicas e privadas; descentralizar 0 atendimento do Crediamigo através da implementação de postos de atendimento informatizados; intensificar ações de divulgação e promoção, visando à fidelização de clientes; desenvolver novos produtos e ampliar o acesso dos clientes a outras linhas de Crédito do BNB; promover avanços no processo de crédito e ampliar o atendimento dos clientes beneficiários do programa Bolsa Família com apoio do Ministério do Desenvolvimento Social e Combate à Fome.

No entanto, alguns problemas do Crediamigo já foram apresentados no seminário Internacional de Microfinanças-BNDES, dentre os quais, destacou-se que alguns profissionais brasileiros questionam se a estrutura geral de um banco estatal de desenvolvimento é apropriada para gerenciar esse programa e sugerem que a divisão de microfinanças se separe do Banco. O programa também enfrentou problemas de recursos humanos e o pessoal contratado para trabalhar no programa Crediamigo quer gozar dos mesmos benefícios de seus colegas que são funcionários da instituição. Verificou-se que uma das características principais em relação à clientela é a maneira de atuação direta nos potenciais clientes, seja por meio de visitas de operadores de crédito diretamente aos bairros, seja por meio de levantamento socioeconômico de regiões com potenciais microempreendedores. A partir da aplicação dos questionários, foi possível concluir que é possível reduzir o nível de burocracia da análise de crédito, aumentando a relação baseada na confiança. Tal procedimento permite que projetos sejam considerados exequíveis por meio de ferramentas como o "credit scoring", que permite maior segurança ao emprestador. Outra maneira de fidelizar o cliente e buscar maior "market share" é a concessão mais rápida do crédito. O investimento em ferramentas de Tecnologia da Informação pode diminuir o tempo entre a entrega de documentos e a concessão em si. Um exemplo seria disponibilizar no website da instituição um simulador de crédito e uma seção disponível com um agente virtual, que pré-aprova o projeto. Interessante implementar este tipo de modalidade, que pode ter potencial. A metodologia do aval solidário, já utilizada pelo BNB, demonstra que a necessidade de garantias pode ser revisada, visto que este processo é mais demorado e acaba excluindo potenciais empreendedores.

No que tange ao empreendimento em si, foi possível verificar que se torna cada vez mais necessário o investimento em pequenos empreendimentos, em detrimento dos grandes, pois o sucesso e a ascensão não estão ligados à grandiosidade do projeto e, sim, à performance dos clientes. Ainda neste tópico, a aposta no produto local demonstra, como destacado nas experiências de sucesso, que é possível um esforço para direcionar investimentos e estudos no mercado local, ao invés de buscar em outros lugares investimentos que podem gerar o mesmo ou até mesmo lucratividade maior. O envolvimento do setor financeiro formal é vital se os esforços pretendem alcançar uma parte significante dos pobres rurais e urbanos de uma determinada área geográfica e para isso devem desenvolver projetos em grande escala, autossuficientes, proveitosos, 
trabalhando em coordenação próxima com bancos locais. O presente estudo não esgota o assunto, servindo como instrumento de pesquisa e avanços para posteriores pesquisas relativas ao tema microcrédito.

Para estudos futuros, cabem as seguintes sugestões:

- estabelecer indicadores específicos para mensuração do impacto do microcrédito na economia local, na qualidade de vida da população como um todo e, principalmente, na dos beneficiários dos programas de microcrédito; e

- Medir o impacto dos programas de microcrédito implementados na Região Nordeste no combate à pobreza no Brasil, visto que esta região é considerada como a de maior índice de pobreza pela ONU.

\section{REFERÊNCIAS}

BARONE, F. M. et al. Introdução ao microcrédito. Brasília: Conselho da Comunidade Solidária, 2002.

BARONE, Francisco Marcelo. Microcrédito e o terceiro setor. Gazeta Mercantil. Rio de Janeiro, p. 65, 02 mar. 2006.

BARONE, Francisco Marcelo; ZOUAIN, Deborah Moraes. Microcrédito. Revista de Administração e Economia, [S.I.], 2008.

BERGER, A.; UNDELL, G. The economics of small business finance: the roles of private equity and debt markets in the financial growth cycle. Journal of Banking and Finance. [s.l.], v. 22, 1998.

CAMINO, David; LARA, Juan. Microfinance And Economic Development In LatinAmerica. [s.I.], 2006.

CARMO, Marcio Lima. O Microcrédito como Tentativa de Democratização do Acesso ao Crédito, no Contexto da Economia Popular e Solidária: um estudo de caso comparativo com o VivaCred/Rocinha. Dissertação de Mestrado. Universidade Federal do Rio de Janeiro - UFRJ, Rio de Janeiro, 2005.

FERNÁNDEZ, F. De qué manera interactúan las IMFs y el Estado para conseguir cambios en el Marco Regulatorio? Experiencia en Ecuador." Strengthening Access to Microfinance and Liberalization Task Order (SALTO) Project. Presented at the 6th Inter-American Forum on Microenterprise. 2003.

FÓRUM DE MICROFINANÇAS. Alternativa que merece mais importância - e crédito. [S.I.], 2007. Disponível em: $<$ http://www.forumdemicrofinancas.org.br/article.php3?id_article=23>. Acesso em: 20 set. 2008.

GOLDMARK, L., POCKROSS, S., VECHINA, D. A situação das Microfinanças no Brasil. SEMINÁRIO INTERNACIONAL BNDES DE MICROFINANÇAS. 2000, Rio de Janeiro. Anais... Rio de Janeiro: BNDS, 2000.

HULME, D.; MOSLEY, P. Finance against poverty. Londres: Routledge, 1996.

IBAM - INSTITUTO BRASILEIRO DE ADMINISTRAÇÃO MUNICIPAL. Perspectivas de expansão das microfinanças no Brasil: marco legal, capitalização e tecnologia. Relatório final. Rio de Janeiro: Ibam, abr. 2001.

LEDGERWOOD, J. Microfinance handbook: an institutional and financial perspective. Washington, D.C.: The World Bank, 1999.

LEDGERWOOD, J. Microfinance Handbook: in Institutional And Financial Perpective. World Bank, Washington, DC, USA, 2001.

MATOS, Franco de. A avaliação Comparativa das atividades de microcrédito Brasil e Bolívia. Dissertação defendida no PROLAM/USP, 2007.

MEZZERA, Jaime. A Organização Internacional do Trabalho. Revista Conjuntura Econômica. [S.I.], 2006.

MORDUCH, J. The microfi nance promise. Journal of Economic Literature, v. XXXVII, p.1.569-1.614, dez. 1999.

MOSLEY, P.; HULME, D. Microentreprise finance: is there a conflict between growth and poverty alleviation? Word Bank. [S.], v.26, n.5, p. 783-790, abr. 1998.

NERI, M.C. Microcrédito, o mistério nordestino e o grammen brasileiro. Rio de Janeiro: FGV/IBRE, CPS, 2008. Disponível em: <http://www.fgv.br/cps/crediamigo>. Acesso: 23 mar.2008.

NERI, Marcelo. Estudo do Perfil Socioeconomico dos Clientes do Crediamigo do BNB. [S.I.], 2004. Disponível em: <http://www.jusbrasil.com.br/noticias/166070/governo-realiza-programa-de-microcredito-produtivo-orientado>. Acesso em: 25 out. 2008.

NERI, Marcelo. Políticas Públicas aos pequenos produtores. Revista Conjuntura Econômica. [S.I.], 2005.

REVISTA DE MICROFINANÇAS. SEBRAE. São Paulo: SEBRAE, Jun.2007.

RIGHETTI, Rios Cesar Buosi. Efeitos do Microcrédito na Geração de Renda em Microempreendimentos: Avaliação de impacto do programa Real Microcrédito. 2008. Tese. [S.I.], 2008.

ROESCH, Sylvia Maria Azevedo. Projeto de estágio e de pesquisa em administração. 3. ed. São Paulo: Atlas, 2006.

ROSALES, Ramon. "Tendencias recientes en la regulación del financiamiento a la microempresa". Presented at the 5th Inter-American Forum on Microenterprise, 2002.

ROSALES, Ramón. Marco jurídico para as instituições de microcrédito .In: SEMINÁRIO INTERNACIONAL BNDES MICROFINANÇAS. 2000, Rio de Janeiro. Anais...Rio de Janeiro: BNDES, 2000. 
SCHARDONG, Ademar. Cooperativa de Crédito: Instrumento de Organização Econômica da Sociedade. Porto Alegre: Editora Rigel, 2002.

SILVEIRA, Caio Márcio. Programa de Apoio aos Pequenos Empreendedores: o Sistema CEAPE. Disponível em: <http://www.iets.org.br/biblioteca/Programa_de_apoio_aos_pequenos_empreendedores_o_sistema_Ceape.pdf Acesso em: 25 out. 2008.

STIGLITZ, J.; GREENWALD, B. Towards a New Paradigm in Monetary Economics. Cambridge: Cambridge University Press, 2003.

YUNNUS, Muhammad. O Banqueiro dos Pobres. 2. ed. São Paulo: Futura: 1999. 